\title{
Coupling System-Based Spatiotemporal Variation and Influence Factors Analysis of City Shrinkage in Henan
}

\author{
Weike Chen ${ }^{1}$, Chaohua Yan ${ }^{1,2 *}$,Wei Li ${ }^{3}$, Yangyang Yang ${ }^{1}$ \\ ${ }^{1}$ School of Management, Tianjin University of Technology, Tianjin, China \\ ${ }^{2}$ School of Business Administration, Henan University of Animal Husbandry and Economy, \\ Zhengzhou, Henan Province, China \\ ${ }^{3}$ School of Economics and Management, Southwest Jiaotong University, Chengdu, Sichuan Province, China
}

Received: 12 October 2020

Accepted: 26 November 2020

\begin{abstract}
Urban shrinkage is an objective historical stage in the process of urban development, and it is also one of the challenges currently facing the process of China's new urbanization. Accurate identification of urban shrinkage is an important premise and foundation that is required to ensure sustainable urban development. Based on the coupling perspective, in this paper, a comprehensive urban shrinkage evaluation system was constructed from the three aspects of population, economy and society to measure the urban shrinkage that occurred in Henan province during the period from 2009 to 2018 . Linear regression analysis was used to evaluate the influencing factors. The results show that the overall shrinkage of Henan province is on the rise. Given the influence of economic foundations and market conditions, different cities in Henan province show different shrinkage rates. Urban shrinkage presents a pattern of high levels in the south and low levels in the north. The dependency ratio of the elderly population and the unemployment rate of the population have aggravated the shrinkage of the study cities. Urban population, birth rate, urban population density, GDP, per capita financial income, total investment in social fixed assets, proportion of tertiary industries, per capita road area, popularization rate of conventional gas, green coverage rate of built-up areas, amount of urban built-up area and population with a certain education level per 100,000 people were shown to restrain the shrinkage. This study provides a useful evaluation method for the determination of urban shrinkage.
\end{abstract}

Keywords: urban shrinkage, dynamic evolution, key impact factors, coupling system

*e-mail: tlgy0909@126.com 


\section{Introduction}

In the first half of the $20^{\text {th }}$ century, when global urbanization was accelerating, Britain's older industrial cities were shrinking. After World War II, some cities in the United States, Japan, Germany, Italy and other countries also experienced shrinking. In the 1980s and 1990s, with the collapse of the Soviet Union, most cities in the former communist countries of Eastern Europe suffered from the trauma of shrinking. From 1990 to 2010, about 20\% of European cities faced the dilemma of population shrinkage, such as the older industrial cities in Britain, Italy, France, Poland, Germany, Greece, Hungary, Czech, and Romania [1]. Among 220 large and medium-sized cities in Europe, 57\% suffered from population loss to some extent from 1996 to 2001 [2]. The United States' Rust Belt, along with the whole of Russia, Kazakhstan, South Africa, South Korea, and other countries are currently still facing severe population shrinking [3-4]. With the new norm of the economy in China, and the rapid development of urbanization, China's local urban shrinkage has gradually become a topic of interest. According to statistics, from 2000 to $2010,26.71 \%$ of prefecturelevel administrative units and $37.16 \%$ of counties and districts in China contracted. However, with the rapid advancement of new urbanization, Chinese cities still have great development potential, which means that Chinese urban shrinkage has different characteristics from that of western countries, owing to the coexistence of population loss and spatial expansion. China's urban shrinkage is a process of the relative loss of urban population, as well as a decline in economic, social and other multi-dimensional factor resources [5]. It is mainly manifested in the slowdown of economic development, the adjustment of industrial structure and the loss of population caused by the change in the population structure. Among China's shrinking cities, the reduction of the local population has not dampened the further increase in the amount of urban construction land, which has fundamentally aggravated the wasting of land resources, the decline of the built environment and the obstruction of economic development - all of these factors have become urgent problems that must be overcome in the process of rapid urbanization in China [6]. Henan Province is located in the middle of China. In recent years, with the continuous development of economic construction, the urbanization rate in this province has also greatly increased, but at the same time, population shrinkage has been observed in some areas. Different from the shrinkage observed in economic recession areas, this population reduction is hidden by the economic development, which is similar to the characteristics of urban shrinkage in other parts of China. We chose Henan Province as the research object to help us better understand the situation of urban shrinkage in China as a whole. Urban shrinkage is a double-edged sword for urban development. It reduces urban population density and produces a large amount of idle land, which creates the possibility for the adjustment of the urban industrial and land use structures. However, this possibility is based on an effective grasp of urban shrinkage. A comprehensive study of urban shrinkage can identify the state and spatial pattern of urban development, and it can also help to realize the objective requirements of high-quality urban development. The findings of this study have important practical significance and far-reaching historical significance for the construction of a scientific and reasonable urban scale system.

The research on urban shrinkage in foreign countries began several decades ago and has produced certain achievements, which are focused on (1) the definition of urban shrinkage, (2) the causes of urban shrinkage, (3) the types of urban shrinkage, (4) the impact of urban shrinkage and (5) the available countermeasures. In 1988, German scholars first proposed the term "urban shrinkage" to describe the massive loss of urban populations and the resulting hollowness of local urban areas [7]. The Shrinking City International Research Network defines a shrinking city as an urban area with a population of more than 10,000 and a steady population loss that occurs for more than two years due to an economic transition process characterized by a certain structural crisis. Defining urban shrinkage by means of population loss is generally accepted [2]. Western academic circles adopt the theoretical framework of the "shrinking city" to analyze population shrinkage and urban recession, and the relevant literature focuses on concept definition, cause mechanism, shrinking mode, impact effect and countermeasures. There is still no unified conclusion regarding the definition of urban shrinkage. Clark believed that urban shrinkage is the decline of quality of life caused by population loss and the resulting rapid increase of unemployment [8]. Martinez posited that urban shrinkage is defined as a loss of urban population that accounts for $10 \%$ of the total population or an average annual loss rate of more than $1 \%$ [9]. Most foreign scholars have classified the influencing factors of population shrinkage in typical European and American countries into four categories: deindustrialization, suburbanization, demographic structure and political factors [10-19]. For example, Gans believed that deindustrialization and economic structural transformation are the main factors that are exacerbating the recession in eastern Germany [10]. Urban shrinkage types can be divided into perforated shrinking and doughnutshaped shrinking. Perforated shrinking is typical of industrial cities in Europe, and it is manifested as the loss of population throughout all areas of the city, and a pattern in which vacancies and abandoned buildings are mixed in with other buildings that are still in use. The doughnut shaped shrinking is most typical in the rust belt of the northeastern United States. In this type of shrinkage, the inner city population of the old 
industrial cities moves out in large numbers, while the suburbs are relatively stable, forming a ring-like shrinking pattern [20]. The most intuitive manifestation of urban shrinkage is the loss of population, but its essence is the loss of resource elements from the city, resulting in the vacancy of houses and land, economic downturn, reduction of fiscal revenue, decline of social public service capacity, etc., which leads to a dilapidated urban landscape, an increase in urban poverty and crime, and serious social differentiation. However, the impact of urban shrinkage is not all negative. The extra urban open space that becomes available due to population loss provides an opportunity for urban ecological reconstruction, which is conducive to expanding urban green space and improving urban biodiversity [21]. From the perspective of countermeasures, there are mainly two types of resistance and adaptation. Resistance attempts to restore the prosperity of the city by means of urban renewal and central urban renewal. Representative cities include Leipzig in Germany and Liverpool in England. Adaptation aims to improve the quality of the urban and ecological environments through smart shrinking and green planning. Representative cities include Youngstown in the United States and Aviles in Spain [22].

On the basis of in-depth research on the existing research results regarding Western urban shrinkage, domestic scholars have also recognized some localized achievements with Chinese characteristics that reflect the actual situation of Chinese urban shrinkage. The research on urban shrinkage in China started earlier in the Beijing City Laboratory. Based on the changes in population density shown by data from the fifth census and the sixth census, Long identified a total of 180 shrinking cities in China and proposed the research framework of urban shrinkage in China [23]. Zhang took prefecture-level city and the administrative units above them as the research object and distinguished the current urban shrinkage pattern in China [24]. Taking population change as the main observation point, $\mathrm{Wu}$ analyzed the shrinking status of urban agglomeration in the Beijing-Tianjin-Hebei region and the Yangtze River Delta by building a measure model of urban shrinkage [25]. Meng studied the shrinkage of Siping, an old industrial city, based on the population shrinkage model, and found that the population of Siping began to decline in 2012, and the shrinkage of the city was on the rise [26]. Wang proposed the concept of economic-population shrinkage [27]. Taking the resource-exhausted cities of Heilongjiang Province as an example, they used a panel data model to measure the impact of income disparity, industrial structure and other factors on urban shrinkage. Measures such as the transformation of the industrial structure can effectively curb urban shrinkage.

First, it can be seen that most of the current literature uses a single index or a single spatial perspective to judge urban shrinkage [28-30]. However, urban shrinkage is not the result of a single factor, but is rather the result of multi-dimensional factors such as urban population, economy and society. Urban shrinkage reduces the total population, and it also affects the level of urban economic development and the quality of life of urban residents. It is easy to adopt a single index of population size, but this is not enough to objectively and clearly reflect the real situation of urban shrinkage, and the measurement accuracy is not high.

Most of the existing literature focuses on the characteristics of the urban shrinkage phenomenon, and few studies discuss the causes of the urban shrinkage phenomenon. The process of urban shrinkage is accompanied by the loss of population, the change in the economy and the adjustment of urban planning [31-32]. Understanding the evolution mechanism of urban shrinkage and mastering the key influencing factors can effectively resolve the adverse effects of urban shrinkage and ensure the sustainable development of cities.

Finally, the existing literature mostly selects specific groups, such as resource-based cities, shrinking cities and urban communities, as research objects [33-34]. The results of the research are not easy to popularize. There is little research on the identification and cause analysis of the shrinkage phenomenon in ordinary cities.

To make a contribution to filling in the gaps left by existing studies, we have studied the issue from the following aspects. First, based on the coupling point of view, this paper constructs an evaluation index system from the three dimensions of population, the economy and society to evaluate the urban shrinkage in Henan Province. Second, a regression model is established to quantitatively analyze the factors affecting urban shrinkage, which can provide a reference for urban development decision-making. Third, we put forward policy suggestions for cities that may be shrinking to help them alleviate this phenomenon, and we also seek to provide some references for the study of urban shrinkage theory.

The remainder of this paper is organized as follows: Chapter 2 carries out the research design and application, establishes the evaluation index system of urban shrinkage, and constructs the evaluation model and linear regression model. The third chapter analyzes and discusses the results, distinguishes between the temporal and spatial dynamic evolution of urban shrinkage in Henan province, and identifies the key influencing factors. The fourth chapter summarizes the process of the paper and puts forward conclusions and suggestions to provide a reference for the evaluation of urban shrinkage. The goals of this paper overall are to accurately identify the phenomenon of urban shrinkage, define the basic characteristics and formation mechanism of urban shrinkage, and provide new ideas for solving China's urban development problems and realizing sustainable urban development. 


\section{Material and Methods}

\section{Study Area}

Henan province, located in central China, is the country's largest grain production base. Its unique geographical location makes it an important aviation, road, rail and energy hub in the country. Henan province has 18 prefecture-level cities with a land area of 167,000 square kilometers. By the end of 2017, the province had a total population of $108,528,500$. Henan province accounts for about $8 \%$ of the national population and $1.74 \%$ of the national land area, which is under great pressure from the process of urban development. In the a recent ten-year period, although Henan province has formed a unique development path, the development level and anti-interference ability of different cities remain quite different. The situation of Henan province is similar to that of most provinces in China. The urban shrinkage in Henan is representative of urban shrinkage all over China, and the research results can be used for reference by other cities.

\section{Data Sources}

The data involved in this study is based on the collection and collation of various indicators of urban development and national economic statistics of the country, of Henan Province and of various cities from 2007 to 2016, and the data is taken from The Statistical Yearbook of China, the Statistical Yearbook of Henan Province and the Urban Construction Yearbook of Henan Province. In addition, in order to facilitate the development of the research, some of the index data is processed technically.

\section{Constructing an Indicator System}

In accordance with the principles of scientificity, directivity, systematicity and data availability, by referring to the existing research results and combining them with the actual development of cities in Henan Province, an urban shrinkage evaluation index system is determined from the three dimensions of population, economy and society. The sources of the indicators are shown in Table 1.

The population dimension includes population size, population growth, population structure, population density and population unemployment. The decline of population scale is the most intuitive sign of urban shrinkage, and population growth can effectively restrain urban shrinkage. Population structure is an important indicator used to measure the vitality and potential of urban development. The higher the proportion of the elderly population, the greater the risk of urban shrinkage. Population density reflects the degree of population concentration in cities, and cities with smaller population density are more likely to shrink. The more people lose their jobs, the more likely cities are to lose population. In this paper, the amount of urban population is selected to reflect the population scale, the birth rate reflects the population growth, the dependency ratio of the aged population reflects the urban population structure, the urban population density reflects the population density, and the population unemployment rate reflects the population unemployment.

Table 1. Urban shrinkage evaluation index system.

\begin{tabular}{|c|c|c|c|}
\hline Target Layer & Criterion Layer & Indicators & Indicial Notation \\
\hline \multirow{14}{*}{ Urban shrinkage } & \multirow{5}{*}{ Population dimension } & Urban population & $\mathrm{X}_{1}$ \\
\hline & & Birth rate & $\mathrm{X}_{2}$ \\
\hline & & Aging population bring-up ratio & $\mathrm{X}_{3}$ \\
\hline & & Urban population density & $\mathrm{X}_{4}$ \\
\hline & & Population of unemployment & $\mathrm{X}_{5}$ \\
\hline & \multirow{4}{*}{ economic dimension } & Gross domestic product & $\mathrm{X}_{6}$ \\
\hline & & Per Capita Revenue & $\mathrm{X}_{7}$ \\
\hline & & Total society fixed asset investment & $\mathrm{X}_{8}$ \\
\hline & & Proportion of tertiary industry & $\mathrm{X}_{9}$ \\
\hline & \multirow{5}{*}{ Social dimension } & Road area per citizen & $\mathrm{X}_{10}$ \\
\hline & & Gas penetration rate & $\mathrm{X}_{11}$ \\
\hline & & Greenery coverage of urban area & $\mathrm{X}_{12}$ \\
\hline & & Urban built-up area & $X_{13}$ \\
\hline & & Educated population per 100000 people & $\mathrm{X}_{14}$ \\
\hline
\end{tabular}


The economic dimension includes economic comprehensive strength, economic development motive force and economic structure. The economy is an important force that promotes the rapid development of cities. The stronger the comprehensive economic strength, the more powerful the economic development force will be, the more the economic structure will be optimized, and the lower the possibility of urban shrinkage will be. GDP and per capita fiscal revenue are mainly selected to reflect the comprehensive strength of the urban economy; total social fixed asset investment is selected to reflect the driving force of urban economic development; and the proportion of tertiary industries is selected to reflect the urban economic structure.

The social dimension includes infrastructure, living environment and education resource density. The ultimate goal of urban development is to provide residents with good public infrastructure, a comfortable living environment and convenient and superior educational conditions. If the city has difficulty meeting even the most basic living and learning needs of residents, then the city is considered to be dilapidated and the possibility of shrinkage is very large. In this paper, the per capita road area and gas penetration rate are selected to reflect the security capacity of the urban infrastructure, the green coverage rate and the area of built-up areas are selected to reflect the urban living environment, and the educational resource density of the educated population per 100,000 people is selected.

\section{Evaluation of Urban Shrinkage}

(1) Non-dimensionalization data processing:

Given that the evaluation standards of the indicators are inconsistent, it is necessary to convert the indicator values to dimensionless values, using the following normalization formula:

Positive indicators:

$$
x_{i j}^{\prime}=\frac{x_{i j}-\min \left(x_{i j}\right)}{\max \left(x_{i j}\right)-\min \left(x_{i j}\right)}
$$

Negative indicators:

$$
x_{i j}^{\prime}=\frac{\max \left(x_{i j}\right)-x_{i j}}{\max \left(x_{i j}\right)-\min \left(x_{i j}\right)}
$$

...where $x_{i}$ is a standardized value, $i=1,2, \ldots \ldots . \mathrm{m}$, $j=1,2, \ldots \mathrm{n}, \min \left(x_{i j}\right)$ is the minimum value, and $\max \left(x_{i j}\right)$ is the maximum value.

The standardized matrix from the standardized values is as follows:

$$
\mathrm{Y}=\left\{y_{i j}\right\} m \times n \quad y_{i j}=\frac{x_{i j}^{\prime}}{\sum_{j=1}^{m} x_{i j}^{\prime}} \quad 0 \leq y_{i j} \leq 1
$$

(2) Calculation of the indicator entropy weight:

The index weight affects the evaluation result, and the objective and fair choice of the index weight is useful to ensuring the quality of the evaluation result. Using the entropy method for reference, formula (4) and formula (5) are used to calculate the index entropy value and weight, respectively.

$$
\begin{aligned}
& \text { Entropy value: } \begin{array}{l}
e_{j}=-\frac{\sum_{i=1}^{m} y_{i j} \ln y_{i j}}{\ln m} \\
\text { Weights: }
\end{array} W_{i}=\frac{1-e_{j}}{\sum_{i=1}^{n}\left(1-e_{j}\right)}
\end{aligned}
$$

(3) Calculation of the urban comprehensive development index:

The standard data for each indicator and weight index are combined to determine the urban vulnerability, which is expressed as:

$$
K_{i}=\sum_{j=1}^{n}\left(w_{i} \dot{x}_{i j}^{\prime}\right) \quad i=1,2, \ldots \ldots \mathrm{m}
$$

....where $w_{i}$ is the entropy weight of $x_{i}$, and $x_{i j}^{\prime}$ is the standardized value.

(4) Calculation of city shrinkage:

$$
\text { shrinking }=\Delta K_{i}=\left(K_{i t 1}-K_{i t 2}\right) \times 100 \%
$$

The change of the comprehensive index is used to measure the urban growth and urban shrinkage. If the urban comprehensive development index drops, it can be defined as the shrinking state of the city; otherwise, it is the growth state. The decline in the development index reflects the degree of urban shrinkage. When $\Delta K i>0$, it means that the city is in the state of growth; $\Delta K i<0$ means the city is shrinking.

(5) Classification of urban shrinkage

Based on the classification method of natural discontinuities and referring to existing studies, cities are divided into four categories: high shrinkage, mild shrinkage, mild growth and high growth, as shown in Table 2.

\section{Analysis of Key Impact Factors}

The change of the urban comprehensive development level is one of the important indexes reflecting the urban shrinkage. Taking the urban comprehensive development index as the dependent variable, the regression model is established. The purpose of the model is to test the relationship between the indicators and the urban comprehensive development index, and to analyze the impact of each index on urban shrinkage. 
Table 2. Criteria for classification of urban shrinkage level

\begin{tabular}{|c|c|c|c|c|}
\hline Shrinkage classification & High shrinkage & Slight shrinkage & Slight increase & Height increase \\
\hline Shrinkage index & $<<-9.44 \%$ & $(-9.44 \%,-4.99 \%]$ & $(-4.99 \%,-0.96 \%]$ & $>-0.96 \%$ \\
\hline
\end{tabular}

In this paper, the following regression model is established:

$$
Y_{i t}=\alpha_{0}+\sum_{i=1}^{14} \alpha_{i} x_{i t}+\mu_{i}+\varepsilon_{i t}
$$

...where, Y represents the comprehensive development index of all prefecture-level cities, $i$ represents all prefecture-level cities, $t$ represents the year, $x_{i}$ represents 14 indicators in the dimensions of population, economy and society, $\varepsilon$ represents the random disturbance term, and $a_{i}$ represents the parameter to be estimated. The static panel model is used to quantitatively analyze the effects of various influencing factors on urban shrinkage.

\section{Results and Discussion}

According to formulas (1)-(7), the comprehensive index of urban development in a recent ten-year period
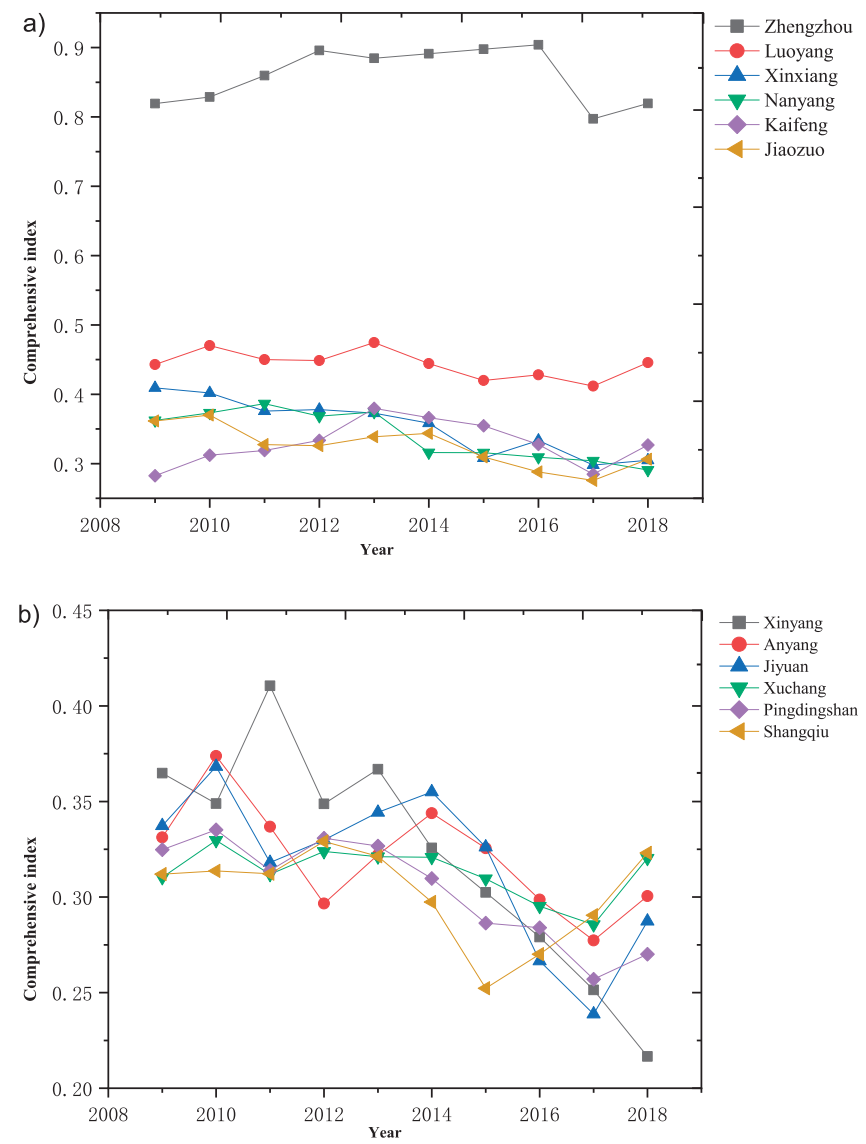

in Henan Province and cities of various other provinces is calculated, as shown in Table 3. The urban shrinkage is analyzed in terms of time sequence and space. The static panel model is used to analyze the influence of each index on urban shrinkage.

\section{An Analysis of the Spatial and Temporal Evolution of Urban Shrinkage}

\section{Time Series Analysis of Urban Shrinkage}

On the whole, the urban development index of Henan province shows a downward trend, and the urban shrinkage trend is obvious. From 2009 to 2018, the comprehensive urban development index of Henan province decreased from 0.3589 to 0.3191 , with a decrease rate of $11.09 \%$. The comprehensive urban development index shows an M-shaped alternating cycle of "slowly rising and slowly falling". The two time stages of 2010-2011 and 2014-2017 show a decreasing range; that is, Henan province is in a state of shrinkage.
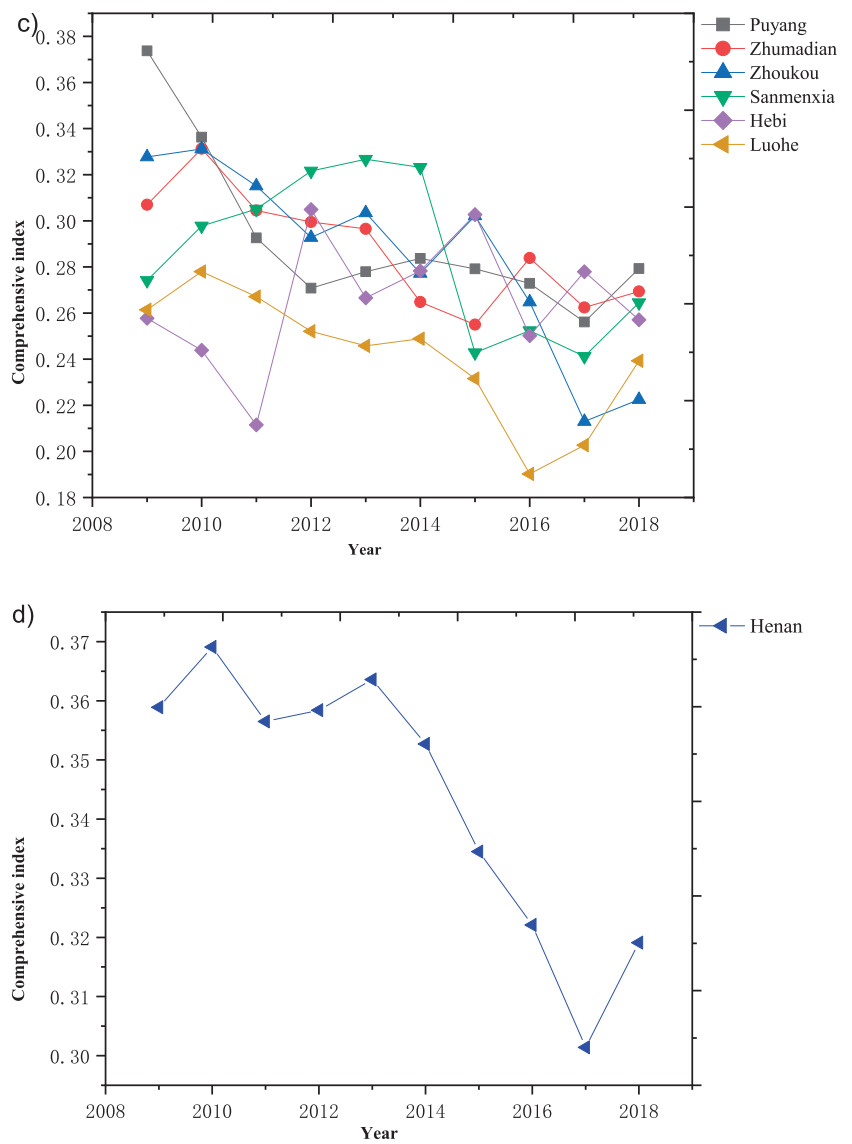

Fig. 1. Comprehensive index of urban development in Henan Province. 
Table 3. The comprehensive index of urban development in recent ten years of Henan Province and various provincial cities.

\begin{tabular}{|c|c|c|c|c|c|c|c|c|c|c|c|}
\hline Year & 2009 & 2010 & 2011 & 2012 & 2013 & 2014 & 2015 & 2016 & 2017 & 2018 & Mean \\
\hline Zhengzhou & 0.8192 & 0.8288 & 0.8596 & 0.8959 & 0.8847 & 0.8911 & 0.8978 & 0.9041 & 0.7972 & 0.8194 & 0.8598 \\
\hline Luoyang & 0.4429 & 0.4702 & 0.45 & 0.4487 & 0.4746 & 0.4443 & 0.4199 & 0.4281 & 0.4119 & 0.4457 & 0.4436 \\
\hline Xinxiang & 0.4093 & 0.402 & 0.3757 & 0.3779 & 0.3729 & 0.3583 & 0.3081 & 0.3334 & 0.298 & 0.3048 & 0.3540 \\
\hline Nanyang & 0.3623 & 0.3733 & 0.3864 & 0.3685 & 0.3744 & 0.316 & 0.3157 & 0.3092 & 0.304 & 0.2908 & 0.3401 \\
\hline Kaifeng & 0.2825 & 0.3122 & 0.3189 & 0.3336 & 0.3797 & 0.3662 & 0.3545 & 0.3277 & 0.2847 & 0.3268 & 0.3287 \\
\hline Jiaozuo & 0.3615 & 0.37 & 0.3275 & 0.3258 & 0.3388 & 0.3436 & 0.3097 & 0.2881 & 0.2758 & 0.3063 & 0.3247 \\
\hline Xinyang & 0.3648 & 0.3489 & 0.4105 & 0.3488 & 0.3669 & 0.3257 & 0.3024 & 0.2791 & 0.2514 & 0.2166 & 0.3215 \\
\hline Anyang & 0.3312 & 0.3738 & 0.3368 & 0.2966 & 0.3221 & 0.3439 & 0.3256 & 0.2987 & 0.2773 & 0.3005 & 0.3207 \\
\hline Jiyuan & 0.3373 & 0.3683 & 0.3181 & 0.3299 & 0.3443 & 0.355 & 0.3261 & 0.2666 & 0.2388 & 0.2874 & 0.3172 \\
\hline Xuchang & 0.3103 & 0.3297 & 0.3119 & 0.3239 & 0.3211 & 0.3208 & 0.3096 & 0.2952 & 0.2856 & 0.3203 & 0.3128 \\
\hline Pingdingshan & 0.3248 & 0.3352 & 0.3139 & 0.3308 & 0.3267 & 0.3097 & 0.2864 & 0.284 & 0.257 & 0.2701 & 0.3039 \\
\hline Shangqiu & 0.312 & 0.3137 & 0.3122 & 0.3291 & 0.3213 & 0.2974 & 0.2523 & 0.2701 & 0.2905 & 0.3231 & 0.3022 \\
\hline Puyang & 0.3737 & 0.3363 & 0.2926 & 0.2708 & 0.2779 & 0.2837 & 0.2792 & 0.2729 & 0.2561 & 0.2793 & 0.2923 \\
\hline Zhumadian & 0.307 & 0.3313 & 0.3045 & 0.2995 & 0.2965 & 0.2648 & 0.255 & 0.2839 & 0.2624 & 0.2694 & 0.2874 \\
\hline Zhoukou & 0.3277 & 0.3312 & 0.3151 & 0.2928 & 0.3035 & 0.2772 & 0.3022 & 0.2648 & 0.213 & 0.2225 & 0.2850 \\
\hline Sanmenxia & 0.2741 & 0.2978 & 0.3051 & 0.3216 & 0.3267 & 0.3232 & 0.2428 & 0.2524 & 0.2412 & 0.2645 & 0.2849 \\
\hline Hebi & 0.2577 & 0.2439 & 0.2115 & 0.3049 & 0.2666 & 0.2783 & 0.3027 & 0.2502 & 0.2779 & 0.2571 & 0.2651 \\
\hline Luohe & 0.2614 & 0.278 & 0.2671 & 0.2521 & 0.2458 & 0.2489 & 0.2316 & 0.1902 & 0.2027 & 0.2393 & 0.2417 \\
\hline Henan & 0.3589 & 0.3691 & 0.3565 & 0.3584 & 0.3636 & 0.3527 & 0.3345 & 0.3221 & 0.3014 & 0.3191 & 0.3436 \\
\hline
\end{tabular}

From the perspective of a single city, because of the different economic base and market conditions, the cities show different shrinkage states. From 2009 to 2018, the city with the highest average of urban comprehensive development level index was Zhengzhou, with the average composite index reaching 0.8598, which is inseparable from its healthy economic, industrial and investment advantages. Although Zhengzhou also showed shrinkage in 2012-2013 and 2016-2017, the shrinking was not large and belongs to the category of relative shrinking. The city with the lowest average value was Luohe, and the average comprehensive index was 0.2417 , which is closely related to this city's relatively simple industrial structure, low proportion of tertiary industries and small urban population. The overall development of the city was weak, and the urban shrinkage belongs to the category of absolute shrinkage. The urban comprehensive development index of the other cities also showed different degrees of decline.

From 2009 to 2011, the urban development index of Zhengzhou, Kaifeng, Sanmenxia and Nanyang showed an upward trend, indicating that their development was in the state of growth at this stage. The development index of Xinxiang, Hebi and Puyang has been declining, and these cities were in a state of shrinkage. The low urban population density is the main reason for the shrinking of Xinxiang City. The imperfect construction of the urban infrastructure in Hebi has affected the development of the city. Other urban development indexes alternated between the states of rising and falling. From 2011 to 2015, there were no cities with a continuously rising development index, and most of the cities alternated between shrinkage and growth. Zhumadian and Luohe have been shrinking, mainly because of the low proportion of tertiary industries, the untenable economic structure and the need to strengthen the construction of their urban infrastructure. From 2015 to 2018, Shangqiu had a rising urban development index. The increasing urban population and the continuous promotion of urban construction put Shangqiu in the state of urban growth. Nanyang city and Xinyang City have been shrinking due to the decrease in the birth rate and urban per capita road area. The development trend of Kaifeng, Jiaozuo and nine other cities showed a v-shaped trend of shrinking growth, while that of yet other cities showed an N-shaped trend of growth-shrinkage-growth.

\section{Analysis of Spatial Evolution of Urban Shrinkage}

According to geographical location, Henan Province is divided into northern Henan (Anyang, Puyang, Hebi, Xinxiang, Jiaozuo, Jiyuan), central Henan (Sanmenxia, Luoyang, Pingdingshan, Zhengzhou, Xuchang, Kaifeng, 
Shangqiu, Luohe, Zhoukou), and southern Henan (Nanyang) , Zhumadian, Xinyang). Using 2016 as a benchmark, we calculated the shrinkage of various cities in 2009, 2011, 2013 and 2015. Arcgis10.2 was used to draw the spatial and temporal dynamic evolution map of shrinking cities in corresponding years, as shown in Fig. 2.

In 2009, there were eight shrinking cities, accounting for $44.44 \%$ of the total cities in the province. Xinyang city, Zhoukou City, Xinxiang City and Puyang City were highly shrinking, while Nanyang City, Pingdingshan City, Jiaozuo City and Jiyuan City were slightly shrinking. There are four cities in northern Henan, two in central Henan and two in southern Henan. In 2012, there were seven shrinking cities, accounting for $38.89 \%$ of the total cities in the province. Xinyang city showed high shrinkage, while Nanyang City, Zhoukou City, Xinxiang City, Pingdingshan City, Sanmenxia City and Zhengzhou showed slight shrinkage. There is one city in northern Henan, four in central Henan and two in southern Henan. In 2015, there were nine shrinking cities, accounting for $50 \%$ of the total number of cities in the province. Xinyang city, Zhoukou City and Zhengzhou city were highly contracted, while Nanyang City, Pingdingshan City, Kaifeng City, Hebi City, Anyang City and Jiyuan City were slightly contracted. There are three cities in northern Henan, four in central Henan and two in southern Henan. In 2017, there were seven shrinking cities, accounting for $38.89 \%$ of the total number of cities in the province. Xinyang city, Nanyang City and Hebi City were highly contracted, while Zhumadian City, Zhoukou City, Pingdingshan City and Xinxiang City were slightly contracted. There are two cities in northern Henan, two in central Henan and three in southern Henan. Overall, city shrinkage shows a pattern of high in the south and low in the north.

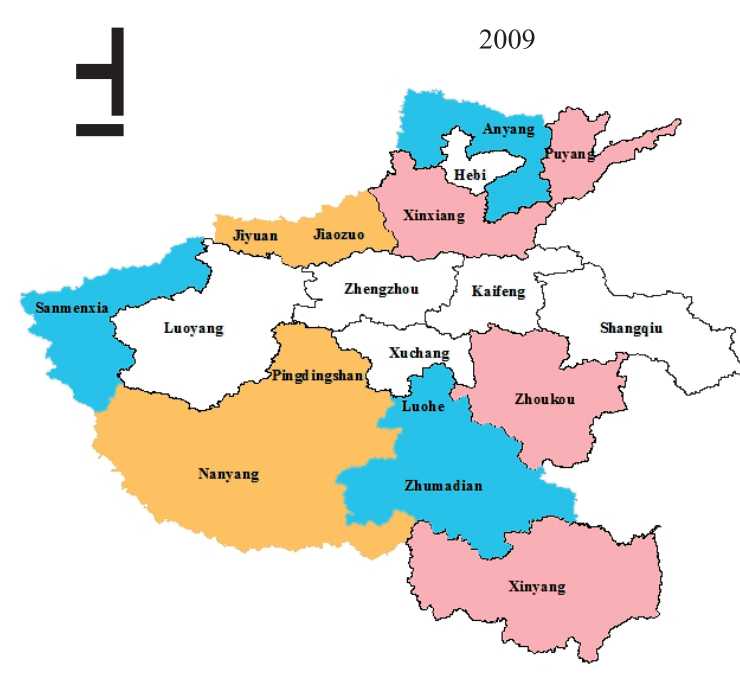

2015

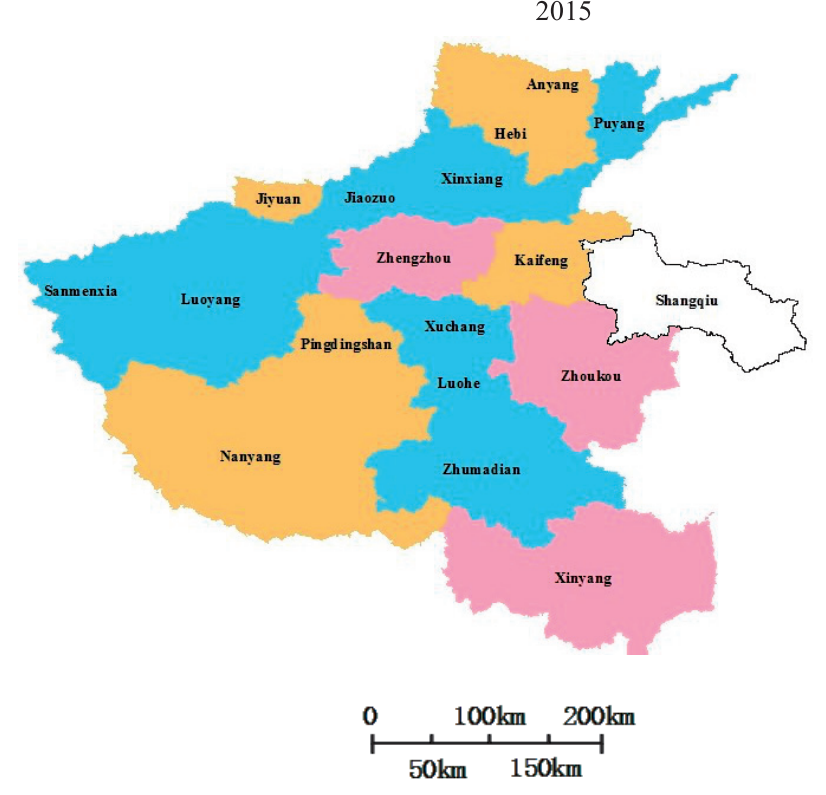

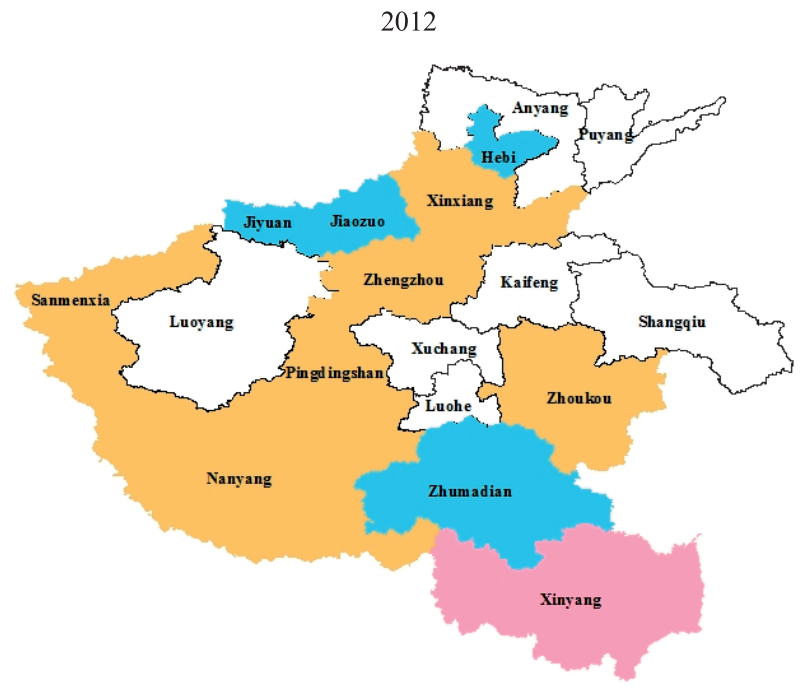

2017

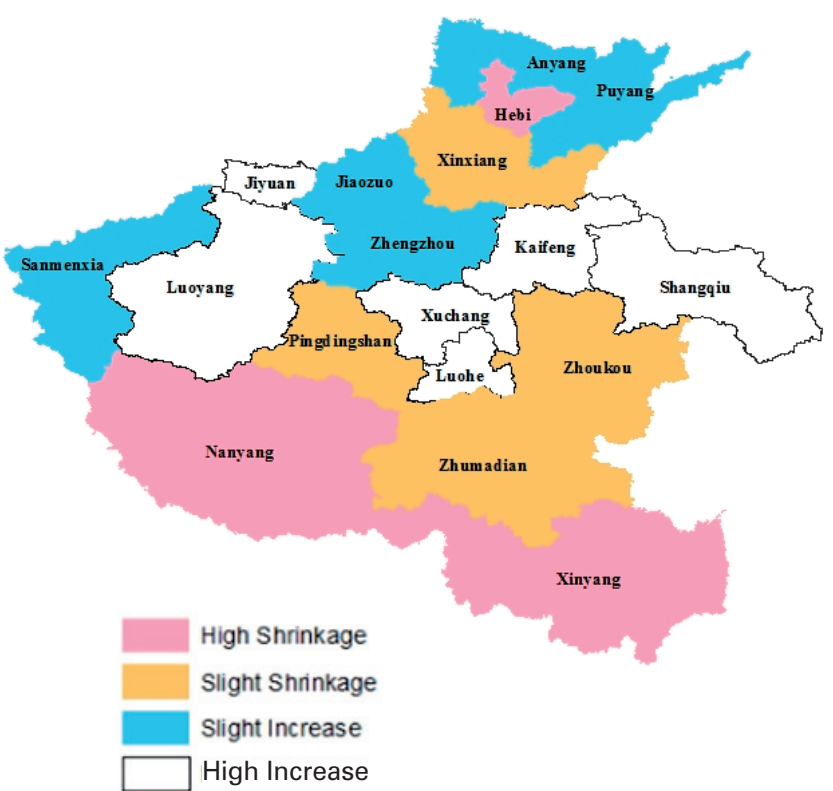

Fig. 2. Spatial distribution map of shrinking city in Henan Province. 


\section{Key Influencing Factor Analysis}

\section{Descriptive Statistical Results}

This paper is based on the municipal panel data of 18 prefecture level cities in Henan Province from 2009 to 2018, including the 10-year time series data of 18 prefecture level cities, with a total of 180 sample observations. In the empirical study, STATA15 was used for analysis, and the statistical results of the variables are shown in Table 4.

\section{Regression Analysis}

After the Hausman test, it is concluded that model (1)-model (14) should be estimated using a fixed-effect model. The regression results of the relationship and the degree of the impact of the various indicators on urban shrinkage are shown in Table 5. It can be seen that the dependency ratio of the elderly population, as well as the population unemployment rate, have a positive effect on the urban shrinkage. Other factors such as the urban population and the birth rate have a negative effect on the urban shrinkage. The correlation coefficient between the proportion of tertiary industries, the per capita fiscal income and the population unemployment rate is relatively large in terms of absolute value, and these three factors are significant influencing factors.

From the perspective of the population dimension, the growth of the urban population, the birth rate and the urban population density have an inhibitory effect on urban shrinkage. The effect of the population birth rate

Table 4. Statistical description of all variables in the econometric model.

\begin{tabular}{|c|c|c|c|c|c|}
\hline Variable & Observations & Mean & Std.Dev & Min & Max \\
\hline $\mathrm{V}$ & 180 & 0.344 & 0.136 & 0.190 & 0.904 \\
\hline $\mathrm{X}_{1}$ & 180 & 237.3 & 133.6 & 33.44 & 743.8 \\
\hline $\mathrm{X}_{2}$ & 180 & 11.25 & 1.028 & 8.830 & 14.90 \\
\hline $\mathrm{X}_{3}$ & 180 & 14.14 & 2.800 & 8.600 & 21.99 \\
\hline $\mathrm{X}_{4}$ & 180 & 5566 & 2808 & 1800 & 15055 \\
\hline $\mathrm{X}_{5}$ & 180 & 3.110 & 0.630 & 1.180 & 4.110 \\
\hline $\mathrm{X}_{6}$ & 180 & 1883 & 1454 & 287.6 & 10143 \\
\hline $\mathrm{X}_{7}$ & 180 & 0.502 & 0.263 & 0.0960 & 1.549 \\
\hline $\mathrm{X}_{8}$ & 180 & 1630 & 1297 & 127.0 & 8468 \\
\hline $\mathrm{X}_{9}$ & 180 & 0.323 & 0.0822 & 0.175 & 0.547 \\
\hline $\mathrm{X}_{10}$ & 180 & 14.34 & 4.678 & 6.020 & 31.65 \\
\hline $\mathrm{X}_{11}$ & 180 & 86.41 & 13.52 & 36.34 & 100 \\
\hline $\mathrm{X}_{12}$ & 180 & 38.97 & 3.956 & 14.80 & 45.87 \\
\hline $\mathrm{X}_{13}$ & 180 & 102.5 & 85.73 & 29.10 & 543.9 \\
\hline $\mathrm{X}_{14}$ & 180 & 61.94 & 75.28 & 1.564 & 261.5 \\
\hline
\end{tabular}

and the urban population density on urban shrinkage is more significant. The dependency ratio of the aged population and the population unemployment rate hinder urban development and further promote urban shrinkage, among which the population unemployment rate plays a more obvious role in urban shrinkage. With the increase in the urban unemployed population, the probability of population migration will increase. The loss of urban population puts the urban population into a shrinking situation, and the phenomenon of urban shrinkage becomes more prominent. From 2009 to 2018 , the dependency ratio of the elderly population in the study 18 cities showed an upward trend, and the urban population structure experienced new changes. The urban population structure is closely related to economic development. As a populous province, Henan has gradually experienced a weakening in the quantity and quality of its labor supply, which is the common reason for the shrinkage of cities in Henan province. The increase in unemployment is the main reason for the slight shrinkage in Zhengzhou. In addition, the unemployment rate in Luoyang, Jiyuan, Xinxiang and Zhoukou has increased to varying degrees, affecting the development of these cities to a certain extent.

From an economic perspective, GDP, per capita financial income, total social fixed asset investment, and the proportion of tertiary industries have important significance for the development of cities. Per capita fiscal revenue and the proportion of tertiary industries have played a more prominent role in promoting urban development. From 2009 to 2018, the GDP of all cities in Henan province showed a trend of growth, with different growth ranges depending on the city. This shows that development is still the main theme of these cities, and shrinkage and development coexist. The per capita fiscal revenue of Xuchang City, Jiyuan City, Xinxiang City, Puyang City and Pingdingshan City has declined to varying degrees even with the overall increasing trend. The per capita fiscal income of Jiyuan decreased from 9,406 yuan in 2014 to 8,355 yuan in 2016, which caused the city to shrink in 2015. The total investment in fixed assets of Pingdingshan, Anyang, Xinxiang and Xinyang is on the rise, but the total investment in the middle years of our study period has decreased year-on-year, which is one of the reasons for the shrinkage of cities in Xinxiang and Xinyang in 2017. In 2014, Luoyang vigorously developed tourism, focused on creating a flat peony culture, promoted the construction of historical and cultural ancient cities, and integrated high-quality resources. The proportion of tertiary industries was significantly improved, and the city's economic development capacity and level were enhanced, effectively curbing the shrinkage of the city.

From the social dimension, the increase in per capita road area, fuel gas penetration rate, green coverage of built-up areas, amount of urban builtup area and the number of people with education attained per 100,000 people have had a positive effect on comprehensive urban development. The per capita 
Table 5. Results of correlation test.

\begin{tabular}{|c|c|c|c|c|c|c|c|}
\hline Model & (1) & (2) & (3) & (4) & (5) & (6) & (7) \\
\hline $\begin{array}{l}\text { Explained } \\
\text { variable }\end{array}$ & $\mathrm{y}$ & $\mathrm{y}$ & $\mathrm{y}$ & $\mathrm{y}$ & $\mathrm{y}$ & $\mathrm{y}$ & $\mathrm{y}$ \\
\hline $\begin{array}{l}\text { Estimation } \\
\text { method }\end{array}$ & $\mathrm{FE}$ & $\mathrm{FE}$ & $\mathrm{FE}$ & FE & FE & FE & FE \\
\hline \multirow{2}{*}{$X_{1}$} & $0.000438 * * *$ & $0.000226 * * *$ & $0.000364 * * *$ & $0.000290 * * *$ & $1.49 \mathrm{e}-06$ & $0.000352 * *$ & $0.000257^{*}$ \\
\hline & $(7.38 \mathrm{e}-05)$ & $(8.40 \mathrm{e}-05)$ & $(7.71 \mathrm{e}-05)$ & $(7.49 \mathrm{e}-05)$ & $(8.19 \mathrm{e}-05)$ & (0.000138) & $(0.000138)$ \\
\hline \multirow{2}{*}{$\mathrm{X}_{2}$} & & $0.0139 * * *$ & $0.00636^{*}$ & $0.00547 *$ & 0.00338 & $0.00512 *$ & $0.00577 * *$ \\
\hline & & $(0.00305)$ & $(0.00341)$ & $(0.00326)$ & $(0.00279)$ & $(0.00277)$ & $(0.00270)$ \\
\hline \multirow{2}{*}{$\mathrm{X}_{3}$} & & & $-0.0107 * * *$ & $-0.00892 * * *$ & $-0.00880 * * *$ & $-0.00898 * * *$ & $-0.0107 * * *$ \\
\hline & & & $(0.00141)$ & $(0.00141)$ & $(0.00137)$ & $(0.00133)$ & $(0.00140)$ \\
\hline \multirow{2}{*}{$\mathrm{X}_{4}$} & & & & $1.02 \mathrm{e}-05^{* * *}$ & $8.06 \mathrm{e}-06^{* * *}$ & $8.48 \mathrm{e}-06 * * *$ & $8.49 \mathrm{e}-06^{* * *}$ \\
\hline & & & & $(2.16 \mathrm{e}-06)$ & $(1.96 \mathrm{e}-06)$ & (1.91e-06) & $(1.86 \mathrm{e}-06)$ \\
\hline \multirow{2}{*}{$X_{5}$} & & & & & $-0.0263 * * *$ & $-0.0270 * * *$ & $-0.0216 * * *$ \\
\hline & & & & & $(0.00528)$ & $(0.00514)$ & $(0.00528)$ \\
\hline \multirow{2}{*}{$\mathrm{X}_{6}$} & & & & & & $2.06 \mathrm{e}-05 * * *$ & $5.45 \mathrm{e}-06$ \\
\hline & & & & & & $(6.58 \mathrm{e}-06)$ & $(7.94 \mathrm{e}-06)$ \\
\hline \multirow{2}{*}{$\mathrm{X}_{7}$} & & & & & & & $0.0910^{* * *}$ \\
\hline & & & & & & & $(0.0284)$ \\
\hline \multicolumn{8}{|l|}{$\mathrm{X}_{8}$} \\
\hline \multicolumn{8}{|l|}{$X_{0}$} \\
\hline \multicolumn{8}{|l|}{$X_{10}$} \\
\hline$\Lambda_{10}$ & & & & & & & \\
\hline \multicolumn{8}{|l|}{$X_{1}$} \\
\hline \multicolumn{8}{|l|}{$X_{12}$} \\
\hline$x_{12}$ & & & & & & & \\
\hline \multicolumn{8}{|l|}{$X_{1}$} \\
\hline \multicolumn{8}{|l|}{$\mathrm{X}_{14}$} \\
\hline & & & & & & & \\
\hline \multirow{2}{*}{ _cons } & $0.448 * * *$ & $0.553 * * *$ & $0.480 * * *$ & $0.406^{* * *}$ & $0.543 * * *$ & $0.610^{* * *}$ & $0.584 * * *$ \\
\hline & $(0.0177)$ & $(0.0286)$ & $(0.0338)$ & $(0.0354)$ & $(0.0358)$ & $(0.0409)$ & $(0.0405)$ \\
\hline $\mathrm{N}$ & 180 & 180 & 180 & 180 & 180 & 180 & 180 \\
\hline
\end{tabular}


Table 5. Continued.

\begin{tabular}{|c|c|c|c|c|c|c|c|}
\hline Model & (8) & (9) & (10) & (11) & (12) & (13) & (14) \\
\hline $\begin{array}{l}\text { Explained } \\
\text { variable }\end{array}$ & $\mathrm{y}$ & $\mathrm{y}$ & $\mathrm{y}$ & $\mathrm{y}$ & $\mathrm{y}$ & $\mathrm{y}$ & $\mathrm{y}$ \\
\hline $\begin{array}{l}\text { Estimation } \\
\text { method }\end{array}$ & FE & $\mathrm{FE}$ & FE & $\mathrm{FE}$ & FE & FE & FE \\
\hline \multirow{2}{*}{$\mathrm{X}_{1}$} & $0.000239 *$ & 0.000201 & 0.000168 & 0.000150 & 0.000153 & 0.000146 & $9.59 \mathrm{e}-05$ \\
\hline & $(0.000143)$ & $(0.000146)$ & $(0.000135)$ & $(0.000132)$ & $(0.000127)$ & $(0.000130)$ & $(0.000124)$ \\
\hline \multirow{2}{*}{$\mathrm{X}_{2}$} & $0.00569 * *$ & $0.00485^{*}$ & 0.00381 & 0.00382 & 0.00350 & 0.00348 & 0.00299 \\
\hline & $(0.00271)$ & $(0.00280)$ & $(0.00259)$ & $(0.00252)$ & $(0.00244)$ & $(0.00245)$ & $(0.00232)$ \\
\hline \multirow{2}{*}{$X_{3}$} & $-0.0105 * * *$ & $-0.00906^{* * *}$ & $-0.00968 * * *$ & $-0.0110 * * *$ & $-0.0122 * * *$ & $-0.0122 * * *$ & $-0.0125 * * *$ \\
\hline & $(-0.00146)$ & $(-0.00188)$ & $(-0.00173)$ & $(-0.00174)$ & $(-0.00172)$ & $(-0.00173)$ & $(-0.00164)$ \\
\hline \multirow{2}{*}{$\mathrm{X}_{4}$} & $8.35 \mathrm{e}-06^{* * *}$ & $8.11 \mathrm{e}-06^{* * *}$ & $1.15 \mathrm{e}-05^{* * *}$ & $1.02 \mathrm{e}-05^{* * *}$ & $8.14 \mathrm{e}-06^{* * *}$ & $8.38 \mathrm{e}-06^{* * *}$ & $9.35 \mathrm{e}-06^{* * *}$ \\
\hline & $(1.89 \mathrm{e}-06)$ & $(1.89 \mathrm{e}-06)$ & $(1.86 \mathrm{e}-06)$ & $(1.86 \mathrm{e}-06)$ & $(1.90 \mathrm{e}-06)$ & $(2.15 \mathrm{e}-06)$ & $(2.06 \mathrm{e}-06)$ \\
\hline \multirow{2}{*}{$\mathrm{X}_{5}$} & $-0.0217 * * *$ & $-0.0219 * * *$ & $-0.0214 * * *$ & $-0.0226^{* * *}$ & $-0.0216^{* * *}$ & $-0.0215 * * *$ & $-0.0235^{* * *}$ \\
\hline & $(-0.00530)$ & $(-0.00529)$ & $(-0.00488)$ & $(-0.00477)$ & $(-0.00462)$ & $(-0.00468)$ & $(-0.00446)$ \\
\hline \multirow{2}{*}{$\mathrm{X}_{6}$} & $8.85 \mathrm{e}-06$ & $2.49 \mathrm{e}-06$ & $2.03 \mathrm{e}-06$ & 7.90e-06 & $7.52 \mathrm{e}-06$ & $5.84 \mathrm{e}-06$ & $2.30 \mathrm{e}-06$ \\
\hline & $(1.06 \mathrm{e}-05)$ & $(1.19 \mathrm{e}-05)$ & $(1.10 \mathrm{e}-05)$ & $(1.08 \mathrm{e}-05)$ & $(1.05 \mathrm{e}-05)$ & $(1.27 \mathrm{e}-05)$ & $(1.20 \mathrm{e}-05)$ \\
\hline \multirow{2}{*}{$X_{7}$} & $0.0917 * * *$ & $0.0962 * * *$ & $0.0846^{* * *}$ & $0.0740 * * *$ & $0.0968 * * *$ & $0.0969 * * *$ & $0.0910 * * *$ \\
\hline & $(0.0285)$ & $(0.0287)$ & $(0.0266)$ & $(0.0261)$ & $(0.0261)$ & $(0.0262)$ & $(0.0249)$ \\
\hline \multirow{2}{*}{$\mathrm{X}_{8}$} & $4.24 \mathrm{e}-06$ & $1.26 \mathrm{e}-06$ & $1.25 \mathrm{e}-06$ & $6.88 \mathrm{e}-06$ & $1.14 \mathrm{e}-05$ & $1.17 \mathrm{e}-05$ & $2.76 \mathrm{e}-06$ \\
\hline & $(8.81 \mathrm{e}-06)$ & $(9.92 \mathrm{e}-06)$ & $(9.17 \mathrm{e}-06)$ & $(9.12 \mathrm{e}-06)$ & $(8.90 \mathrm{e}-06)$ & $(9.05 \mathrm{e}-06)$ & $(8.84 \mathrm{e}-06)$ \\
\hline \multirow{2}{*}{$\mathrm{X}_{9}$} & & 0.108 & $0.145^{*}$ & $0.137 *$ & 0.0999 & 0.0973 & 0.0240 \\
\hline & & $(0.0898)$ & $(0.0831)$ & $(0.0810)$ & $(0.0790)$ & $(0.0800)$ & $(0.0779)$ \\
\hline \multirow{2}{*}{$X_{10}$} & & & $0.00460 * * *$ & $0.00401 * * *$ & $0.00376^{* * *}$ & $0.00380 * * *$ & $0.00338^{* * *}$ \\
\hline & & & $(0.000875)$ & $(0.000875)$ & $(0.000848)$ & $(0.000867)$ & $(0.000829)$ \\
\hline \multirow{2}{*}{$X_{11}$} & & & & $0.000626^{* * *}$ & $0.000564 * * *$ & $0.000568 * * *$ & $0.000639 * * *$ \\
\hline & & & & $(0.000207)$ & $(0.000200)$ & $(0.000202)$ & $(0.000192)$ \\
\hline \multirow{2}{*}{$X_{12}$} & & & & & $0.00196 * * *$ & $0.00198 * * *$ & $0.00168 * * *$ \\
\hline & & & & & $(0.000568)$ & $(0.000575)$ & $(0.000550)$ \\
\hline \multirow{2}{*}{$X_{13}$} & & & & & & $5.62 \mathrm{e}-05$ & $5.39 \mathrm{e}-06$ \\
\hline & & & & & & $(0.000236)$ & $(0.000224)$ \\
\hline \multirow{2}{*}{$\mathrm{X}_{14}$} & & & & & & & $0.000150 * * *$ \\
\hline & & & & & & & $(3.58 \mathrm{e}-05)$ \\
\hline \multirow{2}{*}{ _cons } & $0.578 * * *$ & $0.577 * * *$ & $0.502 * * *$ & $0.483 * * *$ & $0.423 * * *$ & $0.415^{* * *}$ & $0.381 * * *$ \\
\hline & $(0.0429)$ & $(0.0428)$ & $(0.0420)$ & $(0.0414)$ & $(0.0435)$ & $(0.0555)$ & $(0.0533)$ \\
\hline $\mathrm{N}$ & 180 & 180 & 180 & 180 & 180 & 180 & 180 \\
\hline
\end{tabular}

Notes: “***”, “**”, and “*” represents the statistical significance level of $1 \%, 5 \%$ and $10 \%$ respectively. 
road area and the green coverage rate in the built-up area are more significant factors. Strengthening urban infrastructure construction is conducive to promoting economic structural adjustment and development modes of transformation, driving investment and consumption growth, improving the living environment and enhancing the city's comprehensive carrying capacity - all of these factors help to eliminate urban shrinkage. From 2009 to 2018, the average road area per capita in Xinyang City, except for a slight growth in the middle part of the year, has shown a downward trend as a whole, from $17 \mathrm{~m}^{2}$ in 2014 to $15.65 \mathrm{~m}^{2}$ in 2017. To some extent, this has aggravated the urban shrinkage of Xinyang city, placing the city into the state of high shrinkage in 2015 and 2017. In 2015, Xuchang strengthened urban traffic construction, and its per capita road area increased rapidly from $12 \mathrm{~m}^{2}$ in 2015 to $30 \mathrm{~m}^{2}$ in 2017, which played an important role in the sustainable growth of the city. All urban gas penetration rates are increasing. By the end of 2018 , the penetration rate of urban gas had exceeded $95 \%$, and that of Jiyuan had reached $100 \%$, which reflects the effect of urban infrastructure construction - this factor can restrain urban shrinkage to a certain extent. The urban green coverage rate and the urban built-up area are also increasing, which indicates that urban development is a mainstream phenomenon, and shrinkage is an inevitable existing form. The density of educational resources is the embodiment of educational convenience. Convenient educational conditions can promote the living standard of residents and effectively alleviate the urban shrinkage level.

\section{Conclusions}

\section{Major Conclusions}

Aiming at the problem of urban shrinkage, this paper selects evaluation indicators from the three aspects of population, economy and society from the perspective of coupling, and constructs an evaluation model. The shrinkage of cities in Henan province in a recent ten-year period is measured and analyzed from the perspective of time sequence and spatial evolution. The static panel model is used to conduct quantitative research on the influence of each influencing factor and identify the key influencing factors. The findings are as follows:

First, the transformation from expansion to shrinkage has become a new trend in urban development. From 2009 to 2018, the overall urban development index of cities in Henan Province and certain other cities showed a downward trend, and the local shrinking trend was obvious. The comprehensive index of urban development in Henan Province decreased from 0.3589 to 0.3191 , with a decline rate of $11.09 \%$, and showed an M-type trend of "slowly rising-slowly falling" alternating cycles.
Second, the shrinkage of the study cities showed heterogeneity. Affected by their economic base and market conditions, different cities contracted differently. The comprehensive development index of Zhengzhou was high, and the shrinkage was not obvious, which can be regarded as a state of relative shrinkage. The comprehensive development index of Zhoukou was low, the population loss was serious, and the shrinkage was obvious. Overall, cities in the south contracted more than those in the north.

Third, the dependency ratio of the elderly population and the unemployment rate of the population have aggravated the shrinkage of the study cities. Urban population, birth rate, urban population density, GDP, per capita financial income, total investment in social fixed assets, proportion of tertiary industries, per capita road area, popularization rate of conventional gas, green coverage rate of built-up areas, amount of urban built-up area and population with a certain education level per 100,000 people were shown to restrain the shrinkage.

\section{Implications}

This paper provides a reference method for the judgment of urban shrinkage. The empirical analysis is basically consistent with the actual development of each city, which verifies the feasibility of the method and makes a certain theoretical contribution to the study of urban shrinkage. In addition, we should acknowledge the objective existence of urban shrinkage and adopt positive coping strategies to solve the problems of urban shrinkage and achieve the sustainable development of cities. Based on the above empirical results, we put forward the following suggestions:

First, we should take an objective view of the shrinkage of cities. The alternate rise and fall of this shrinkage is the objective law of urban development, and expansion is not the only standard path for urban development. Under the influence of the growth model, the pursuit of unlimited growth and expansion has dominated urban development. Against the background of the new normal and urban shrinkage, we should change the value orientation of urban development, abandon the pursuit of urban space expansion, pay attention to the quality of urban development, and seek healthy and sustainable development given limited space.

Second, we should accelerate industrial transformation and upgrading, and enhance the economic strength of cities. Adjust the industrial structure may help to solve the problem of decreasing resources and a deteriorating environment, increase the development of tertiary industries on the basis of maintaining the traditionally advantageous industries, and then drive the development of the entire city and reduce urban shrinkage.

Third, we should increase job opportunities and strengthen the introduction of talent. To strengthen 
urban infrastructure construction and develop diversified industries, prefecture-level cities should provide more jobs to retain talent according to their geographical advantages and geographical conditions. We should increase investment in science and technology and talent, pay attention to the introduction and training of talent, and improve the "rainbow effect" of cities, so as to encourage talented people to move to cities and remain living in them for a long period of time.

Fourth, we should adjust and optimize the labor force structure. The government can study and promulgate the policy of increasing the retirement age gradually to solve the aging problem to some extent. We will continue to implement the two-child policy across the board in China, increase the supply of labor, and promote balanced population development. In a word, city managers should respect the objective fact of urban shrinkage and take various measures to ensure the healthy and sustainable development of cities.

This study has some limitations. First, the data used in the study is based on the data of the city yearbook and the census, which is slightly lagged. Second, taking prefecture-level cities as research units, the differentiation law of spatial and temporal dynamics of the urban shrinkage degree is still insufficient in terms of accuracy. Therefore, further research on the subject appears warranted.

\section{Acknowledgements}

This study was supported by the National Social Science Foundation Project of China under Grant (NO. 17BGL210).

\section{Conflict of Interest}

The authors declare no conflict of interest.

\section{References}

1. NUNES R. Book Review: Shrinking Cities: Volume 1: International Research. Urban Studies. 45 (5-6), 1301, 2008.

2. WIECHMANN T., BONTJE M. Responding to Tough Times: Policy and Planning Strategies In Shrinking Cities. European Planning Studies. 23 (1), 1, 2015.

3. HOWE S.R., BIER T., ALLOR D. The shrinking central city amidst growing suburbs: case studies of OHIO's inelastic cities. Urban Geography. 19 (8), 714, 1998.

4. HOEKVELD JOSJE J. Time-Space Relations and the Differences Between Shrinking Regions. Built Environment. 38 (2), 179, 2012.

5. DU Z., ZHANG H., YE Y., JIN L., XU Q. Urban shrinkage and growth: Measurement and determinants of economic resilience in the Pearl River Delta[J]. Journal of Geographical Sciences, 29 (8), 1331, 2019.
6. YANG Z. Sustainability of Urban Development with Population Decline in Different Policy Scenarios: A Case Study of Northeast China[J]. Sustainability, 11 (22), 6442, 2019.

7. HATTORI K., KAIDO K., MATSUYUKI M. The development of urban shrinkage discourse and policy response in Japan. Cities. 69, 124, 2017.

8. CLARK T.N. Amenities drive urban growth. Journal of Urban Affairs. 5, 493, 1989.

9. MARTINEZ-FERNANDEZ C., AUDIRAC I., FOL S., CUNNINGHAM-SABOT E. Shrinking Cities: Urban Challenges of Globalization. International Journal of Urban \& Regional Research. 36 (2), 213, 2012.

10. GANS, PAUL, KEMPER, FRANZ J. Ost-WestWanderungen in Deutschland-Verlust von Humankapital für die neuen Länder? Geographische Rundschau. 55 (6), 16,2003

11. HAASE A., RINK D., GROSSMANN K. Conceptualizing Urban Shrinkage. Environment and Planning A. 7, 1519, 2014.

12. MYKHNENKO V., TUROK I. East European citiespatterns of growth and decline, 1960-2005. International Planning Studies. 4, 311, 2008.

13. KIM S. Design strategies to respond to the challenges of shrinking city. Journal of urban design. 24 (1), 49, 2019.

14. WEAVER R., HOLTKAMP C. Geographical Approaches to Understanding Urban Decline:From Evolutionary Theory to Political Economy. Geography Compass. 9 (5), 286, 2015.

15. DUBEAUX S., SABOT E C. Maximizing the potential of vacant spaces within shrinking cities, a German approach. Cities. 75, 6, 2018.

16. CHRIS R., KAYLA P., KERRY A. Asset or Liability? Ecological and Sociological Tradeoffs of Urban Spontaneous Vegetation on Vacant Land in Shrinking Cities. Sustainability. 10 (7), 2139, 2018.

17. 1BERGLUND L. The Shrinking City as a Growth Machine: Detroit's Reinvention of Growth through Triage, Foundation Work and Talent Attraction. International Journal of Urban and Regional Research. 2, 219, 2020.

18. YOON J., LEE S. A Study on the Urban Planning's Implications and the Governmental Policies for Shrinking City in Japan - Focusing on Location Normalization Plan. Journal of Korea Planning Association. 54 (2), 17, 2019.

19. MABON, LESLIE, SHIH. Management of sustainability transitions through planning in shrinking resource city contexts: an evaluation of Yubari City, Japan. Journal of Environmental Policy \& Planning. 20 (4), 482, 2018.

20. SCHETKE S., HAASE D. Multi-criteria assessment of socio-environmental aspects in shrinking cities: Experiences from Eastern Germany. Environmental Impact Assessment Review. 28 (7), 483, 2008.

21. HAASE D., HAASE A., RINK D. Conceptualizing the nexus between urban shrinkage and ecosystem services. Landscape \& Urban Planning. 132, 159, 2014.

22. XU B., PANG D.L. From shrinkage to Growth: A Comparative Study of urban development in Leipzig and Liverpool. Economist. 7, 79, 2015.

23. LONG Y., WU K., WANG J.H. Shrinking Cities in China. Modern Urban Research. 9, 20, 2015.

24. ZHANG X.L., LIU Y.B., LV C.C. The Background, Identification of Shrinking Cities in China and their Characteristic analysis. Journal of Southeast University (Philosophy and Social Science). 18 (04), 132, 2016.

25. WU K., LONG Y., YANG Y. Urban Shrinkage in the Beijing-Tianjin-Hebei Region and Yangtze River Delta: 
Pattern, Trajectory and Factors. Modern Urban Research. 9, 26, 2015.

26. MENG X.F, WANG D.Y., LI H. Correlation between Urban shrink and Urban Compactness Ratio in Old Industrial City: Taking Siping City in Jilin Province as an Example. Economic Geography. 39 (04), 67, 2019.

27. WANG C.J., QU Y.Y., WU X.H. A Study on EconomicPopulation Shrinkage Governance in Resource-exhausted Cities: A Realistic Analysis Based on Resource-exhausted Cities in Heilongjiang Province. Macroeconomics. 8, 156, 2019.

28. DRINGER S., UCHIYAMA Y., PENKER M., KOHSAKA R. A meta-analysis of shrinking cities in Europe and Japan. Towards an integrative research agenda[J]. European Planning Studies, 4, 1, 2019.

29. WOLFF M., WIECHMANN T. Urban growth and decline: Europe's shrinking cities in a comparative perspective 1990-2010[J]. European Urban and Regional Studies, 25 (2), 122, 2017.
30. RUNGE A., RUNGE J., KANTOR-PIETRAGA I., KRZYSZTOFIK R. Does urban shrinkage require urban policy? The case of a post-industrial region in Poland[J]. Regional Studies, Regional Science, 7 (1), 476, 2020.

31. JAROSZEWSKA E. Urban Shrinkage and Regeneration of an Old Industrial City: the Case of Wałbrzych in Poland[J]. Quaestiones Geographicae, 38 (2), 75, 2019.

32. WICHOWSKA A. Shrinking municipalities and their budgetary revenues on the example of the WarmianMasurian Voivodeship in Poland[J]. Oeconomia Copernicana, 10 (3), 419, 2019.

33. GIRARDIN A. The Plagwitz district in Leipzig: Twenty years of revaluation between managing urban shrinkage and entrepreneurial policies of attractiveness[J]. Geographie, economie, societe, 21 (1), 23, 2019.

34. ORTIZz-MOYA F. Green growth strategies in a shrinking city: Tackling urban revitalization through environmental justice in Kitakyushu City, Japan[J]. Journal of Urban Affairs, 42 (3), 312, 2020. 